\title{
Further Studies of the Genus Methylobacterium and Description of Methylobacterium aminovorans sp. nov.
}

\author{
TEIZI URAKAMI, ${ }^{1 *}$ HISAYA ARAKI, ${ }^{2}$ KEN-ICHIRO SUZUKI,${ }^{3}$ AND KAZUO KOMAGATA ${ }^{4} \dagger$ \\ Biochemicals Division, Mitsubishi Gas Chemical Co., Seavans-N Building, Shibaura, Minato-ku, Tokyo 105, ${ }^{1}$ \\ Niigata Research Laboratory, Mitsubishi Gas Chemical Co., Tayuhama, Niigata 950-31, ${ }^{2}$ \\ Japan Collection of Microorganisms, The Institute of Physical and Chemical Research, \\ Wako-shi, Saitama 351-01, ${ }^{3}$ and Institute of Applied Microbiology, \\ The University of Tokyo, Bunkyo-ku, Tokyo $113,{ }^{4}$ Japan
}

\begin{abstract}
Pink-pigmented facultatively methylotrophs belonging to the genus Methylobacterium were examined in this study. Methylobacterium strains are divided into eight species on the basis of phenotypic characteristics. This division is supported by the results of DNA-DNA homology experiments. On the basis of DNA relatedness and other characteristics, a new species, Methylobacterium aminovorans, is proposed. The type strain of M. aminovorans is strain TH-15 (= JCM 8240).
\end{abstract}

Previously $(39,40,43-45)$, we described the separation of gram-negative methanol-utilizing bacteria into 11 groups on the basis of morphological characteristics, assimilation of carbon compounds, DNA base composition, cellular fatty acid composition, ubiquinone system, and electrophoretic characteristics of enzymes. The group 2 bacteria that we described are facultatively methylotrophic, non-spore-forming, pink-pigmented, polarly flagellated (some strains have a subpolar or lateral flagellum [12]), gram-negative, rodshaped organisms that have a ubiquinone 10 system and a cellular fatty acid composition that includes a large amount of $\mathrm{n}-\mathrm{C}_{18: 1}$ acid. In 1984, we (41) proposed the new genus Protomonas for the bacteria belonging to this group and described a single species, Protomonas extorquens. Furthermore, we described biovars 1, 2, and 3 of Protomonas extorquens on the basis of the assimilation of carbon compounds. However, this species was renamed Methylobacterium extorquens (Urakami and Komagata 1984) comb. nov. corrig. by Bousfield and Green (4).

More recently, we examined the bacterial biodegradation of tetramethylammonium hydroxide (TMAH) and $N, N$-dimethylformamide (DMF) by the following organisms: $A m i$ nobacter aganoensis TH-3 $(35,37)$, Aminobacter niigataensis DM-81 $(37,38)$, Paracoccus aminophilus DM-15 $(36,38)$, Paracoccus aminovorans DM-82 (16, 17, 36, 38), and strain TH- $-15^{\mathrm{T}}$ ( $\mathrm{T}=$ type strain) (35). Strain $\mathrm{TH}-15^{\mathrm{T}}$ was a gramnegative, polarly flagellated, rod-shaped, pink-colony-forming bacterium. It utilized methanol, TMAH, and DMF, but not methane. It had a ubiquinone 10 system, a cellular fatty acid composition that included a large amount of $n-C_{18: 1}$ acid, and a hydroxy fatty acid composition that included a large amount of 3-hydroxy $\mathrm{C}_{14: 0}$ acid. This bacterium should be included in the genus Methylobacterium, as reported previously (35).

In this paper we present a detailed recharacterization of Methylobacterium strains which includes phenotypic characteristics, phospholipid composition data, and DNA relatedness data and propose a new species, Methylobacterium aminovorans.

\footnotetext{
* Corresponding author.

† Present address: Department of Agricultural Chemistry, Tokyo University of Agriculture, Sakuragaoka 1-1-1, Setagaya-ku, Tokyo 156 , Japan.
}

\section{MATERIALS AND METHODS}

Bacterial strains. The strains which we studied are shown in Table 1. Names which do not appear on the Approved Lists of Bacterial Names (31) are enclosed in quotation marks. Strain TH-15 ${ }^{\mathrm{T}}$ was isolated as a TMAH-utilizing bacterium by us (35). Methylobacterium organophilum TK $0047^{\mathrm{T}}$ and "Pseudomonas methanica" TK 0048 were originally isolated as methane-utilizing bacteria $(27,42)$. A pinkpigmented facultatively methylotrophic bacterium, "Mycoplana rubra" TK 0002, was deposited in the National Collection of Industrial Bacteria, Aberdeen, United Kingdom, by M. R. Rhodes. All strains used in this study were maintained on medium B (41) or PYG agar (pH 7.0) (46).

Identification methods. Morphological and physiological characteristics of strain TH-15 ${ }^{\mathrm{T}}$, Methylobacterium organophilum TK $0047^{\mathrm{T}}$, "Pseudomonas methanica" TK 0048, Methylobacterium fujisawaense TK $0065^{\mathrm{T}}$, Methylobacterium radiotolerans TK 0066 and TK 0067 , and strains TK 0068 and TK 0069 were determined as described previously (41). Utilization of the following carbon compounds was determined for all bacterial strains: TMAH, DMF, $N$-methylformamide, formamide, D-fucose, L-asparatic acid, L-glutamic acid, betaine acid, sebacic acid, DL-tartaric acid, pimelic acid, suberic acid, azelaic acid, adipic acid, levulinic acid, mesaconic acid, citraconic acid, and caprylic acid. Each of these compounds was added at a concentration of $0.15 \%$ (wt/vol).

DNA base composition. DNAs were extracted by the method of Saito and Miura (30), and guanine-plus-cytosine $(\mathrm{G}+\mathrm{C})$ contents were determined by reverse-phase highperformance liquid chromatography (HPLC) as described by Tamaoka and Komagata (32).

Cellular fatty acid and hydroxy fatty acid compositions. Cellular fatty acid composition and hydroxy fatty acid composition were determined as described previously (44).

Quinone and quinone homologs. Quinone systems were determined as described previously (43). In the designations used for ubiquinones, the number indicates the number of isoprenoid units in the side chain (e.g., ubiquinone 9, ubiquinone 10 , etc.).

Squalene and steroids. Squalene and steroids were determined as described previously (43).

Pigments. Carotenoid and bacteriochlorophyll pigments were detected by the method described previously $(41,43)$. 
TABLE 1. Bacterial strains studied

\begin{tabular}{|c|c|c|c|c|}
\hline Strain & Other designation(s) & Species & Synonym & Reference(s) \\
\hline TK $0001^{\mathrm{T}}$ & NCIB $9399^{\mathrm{T}}$, JCM $2802^{\mathrm{T}}$ & Methylobacterium extorquens & Protomonas extorquens & $4,12,19,41$ \\
\hline TK 0002 & NCIB 10409, JCM 2803 & & "Mycoplana rubra" & 41 \\
\hline TK 0003 & NCIB 2879, JCM 2804 & Methylobacterium extorquens & "Protaminobacter ruber" & $4,12,41$ \\
\hline TK 0004 & NCIB 9133, JCM 2805 & Methylobacterium extorquens & Pseudomonas sp. & $4,12,41$ \\
\hline TK 0005 & NCIB 9686, JCM 2806 & Methylobacterium extorquens & Pseudomonas sp. & $4,12,41$ \\
\hline TK 0006 & ATCC 21611, JCM 2807 & & "Protaminobacter ruber" & 41 \\
\hline TK 0007 & ATCC 21612 , JCM 2808 & & "Protaminobacter nuber" & 41 \\
\hline TK 0008 & ATCC 21613, JCM 2809 & & "Protaminobacter nuber"' & 41 \\
\hline TK 0009 & ATCC 21614, JCM 2810 & Methylobacterium rhodesianum & "Protaminobacter ruber" & 13,41 \\
\hline TK $0010^{\mathrm{T}}$ & ATCC $14821^{\mathrm{T}}, \mathrm{JCM} 2811^{\mathrm{T}}$ & Methylobacterium rhodinum & Pseudomonas rhodos & $12,15,41$ \\
\hline TK 0012 & NCIB 10598, JCM 2812 & Methylobacterium rhodesianum & "Pseudomonas rosea" & 13,41 \\
\hline TK 0013 & NCIB 10599, JCM 2813 & Methylobacterium rhodesianum & "Pseudomonas rosea" & 13,41 \\
\hline TK 0014 & NCIB 10600, JCM 2814 & Methylobacterium rhodesianum & "Pseudomonas rosea" & 13,41 \\
\hline TK 0015 & NCIB 10602 , JCM 2815 & Methylobacterium rhodesianum & "Pseudomonas rosea" & 13,41 \\
\hline TK 0016 & NCIB 10611 , JCM 2816 & Methylobacterium rhodesianum & "Pseudomonas rosea" & 13,41 \\
\hline TK 0017 & NCIB 10601, JCM 2817 & Methylobacterium rhodesianum & "Pseudomonas rosea" & 13,41 \\
\hline TK 0018 & NCIB 10603, JCM 2818 & Methylobacterium zatmanii & "Pseudomonas rosea" & 13,41 \\
\hline TK 0019 & NCIB 10606, JCM 2819 & Methylobacterium zatmanii & "Pseudomonas rosea" & 13,41 \\
\hline TK 0020 & NCIB 10607, JCM 2820 & Methylobacterium zatmanii & "Pseudomonas rosea" & 13,41 \\
\hline TK 0021 & NCIB 10608, JCM 2821 & Methylobacterium zatmanii & "Pseudomonas rosea" & 13,41 \\
\hline TK 0022 & NCIB 10609, JCM 2822 & Methylobacterium zatmanii & "Pseudomonas rosea" & 13,41 \\
\hline TK 0023 & NCIB 10610, JCM 2823 & Methylobacterium zatmanii & "Pseudomonas rosea" & 13,41 \\
\hline TK 0024 & NCIB 10612, JCM 2824 & Methylobacterium zatmanii & "Pseudomonas rosea" & 13,41 \\
\hline TK 0025 & NCIB 10604, JCM 2825 & Methylobacterium zatmanii & "Pseudomonas rosea" & 13,41 \\
\hline TK $0027^{\mathrm{T}}$ & NCIB $12249^{\mathrm{T}}$ & Methylobacterium rhodesianum & Pseudomonas sp. & $7,13,28,41$ \\
\hline TK $0028^{\mathrm{T}}$ & NCIB $12243^{T}$ & Methylobacterium zatmanii & Pseudomonas sp. & $7,13,28,41$ \\
\hline TK 0029 & ATCC 21438, JCM 2827 & & Pseudomonas sp. & 41 \\
\hline TK $0034^{\mathrm{T}}$ & ATCC $29983^{\mathrm{T}}$, JCM $2829^{\mathrm{T}}$ & Methylobacterium mesophilicum & Pseudomonas mesophilica & $2,12,41$ \\
\hline TK 0035 & IAM 12099, JCM 2830 & Methylobacterium radiotolerans & Pseudomonas radiora & $12,18,41$ \\
\hline TK $0036^{T}$ & IAM $12098^{\mathrm{T}}$, JCM $2831^{\mathrm{T}}$ & Methylobacterium radiotolerans & Pseudomonas radiora & $12,18,41$ \\
\hline TK 0037 & Tonomura et al. K-62 & & Pseudomonas sp. & 33,41 \\
\hline TK 0038 & Mizoguchi et al. TK-7 & & "Thiobacillus rubellus" & 25,41 \\
\hline TK 0039 & Kouno and Ozaki no. 617 & Methylobacterium fujisawaense & & $13,22,41$ \\
\hline TK 0040 & ATCC 35064 & & & 6,41 \\
\hline TK 0042 & Urakami and Komagata BP-3 & & & 41 \\
\hline TK 0043 & Urakami and Komagata BP-11 & & & 41 \\
\hline TK 0044 & Urakami and Komagata BP-22 & & & 41 \\
\hline TK 0045 & Urakami and Komagata BP-41 & & & 41 \\
\hline TK $0047^{\mathrm{T}}$ & ATCC $27886^{\mathrm{T}}, \mathrm{JCM} 2833^{\mathrm{T}}$ & Methylobacterium organophilum & & 27,42 \\
\hline TK 0048 & NRRL B-3449, JCM 2834 & & "Pseudomonas methanica" & 42 \\
\hline TK $0065^{\mathrm{T}}$ & NCIB $12417^{\mathrm{T}}$ & Methylobacterium fujisawaense & & 13,16 \\
\hline TK 0066 & NCIB 9142 & Methylobacterium radiotolerans & Pseudomonas sp. & 13,16 \\
\hline TK 0067 & NCIB 9143 & Methylobacterium radiotolerans & Pseudomonas sp. & 13 \\
\hline TK 0068 & NCIB 9141 & & & 13,16 \\
\hline TK 0069 & NCIB 9145 & & & 13,16 \\
\hline $\mathrm{TH}-15^{\mathrm{T}}$ & & & & 35 \\
\hline
\end{tabular}

Phospholipid composition. Lipids were extracted by the procedure of Bligh and Dyer (3). Phospholipid compositions were determined by the method of Goldberg and Jensen (8).

DNA-DNA hybridization. DNA-DNA hybridization was carried out at $68^{\circ} \mathrm{C}$ by using the method of Kaneko et al. (20). DNAs from Methylobacterium extorquens TK $0001^{\mathrm{T}}$, Methylobacterium onganophilum TK $0047^{\mathrm{T}}$, Methylobacterium rhodinum TK $0010^{\mathrm{T}}$, strain $\mathrm{TH}-15^{\mathrm{T}}$, and Methylobacterium mesophilicum TK $0034^{\mathrm{T}}$ were labeled with $\left[1^{\prime}, 2^{\prime}, 5-{ }^{3} \mathrm{H}\right] \mathrm{dCTP}$ by the nick translation method, using a type TRK 7000 kit (Amersham International plc, Amersham, United Kingdom). DNA-DNA hybridization experiments were performed with Methylobacterium extorquens TK $0001^{\mathrm{T}}$, Methylobacterium organophilum TK 0047 , "Pseudomonas methanica" TK 0048, Methylobacterium rhodinum TK $0010^{\mathrm{T}}$, Methylobacterium zatmanii TK 0025 , strain TH-15 ${ }^{\mathrm{T}}$, Methylobacterium radiotolerans TK $0036^{\mathrm{T}}$, Methylobacterium mesophilicum TK $0034^{\mathrm{T}}$, and "Thiobacillus rubellus" TK 0038.

\section{RESULTS}

Phenotypic characteristics of pink-pigmented facultatively methylotrophic bacteria. Strain TH-15 ${ }^{\mathrm{T}}$, Methylobacterium organophilum TK $0047^{\mathrm{T}}$, "Pseudomonas methanica" TK 0048, Methylobacterium fujisawaense TK $0065^{\mathrm{T}}$, Methylobacterium radiotolerans TK 0066 and TK 0067, and strains TK 0068 and TK 0069 were gram-negative, non-sporeforming, rod-shaped organisms. Their cells were 0.8 to 1.2 by 1.5 to $4.0 \mu \mathrm{m}$ and had rounded ends. The cells occurred singly, rarely in pairs, and were motile by means of a single polar flagellum. Some cells had a subpolar or lateral flagellum. Granules of poly- $\beta$-hydroxybutyric acid accumulated in the cells. A pink or red water-insoluble pigment was produced, but a water-soluble fluorescent pigment was not produced by any of the strains on King B medium. Lighter pink colonies appeared frequently, and colorless colonies appeared rarely. The methyl red and Voges-Proskauer tests 
were negative. Indole and hydrogen sulfide (triple sugar iron medium) were not produced. Hydrolysis of gelatin and starch was not observed. Ammonia was not produced. Acid was produced oxidatively from sugars but was not produced fermentatively. Ammonia, nitrate, and urea were assimilated as nitrogen sources. Urease, oxidase, and catalase were produced. Good growth was observed between $\mathrm{pH} 6.0$ and 8.0. All bacteria tested grew at $30^{\circ} \mathrm{C}$. Growth did not occur in the presence of $3 \%$ sodium chloride. These characteristics were identical to those of other Methylobacterium strains (41).

All of the strains used in this study grew at the expense of methanol, glycerol, and succinic acid, but did not grow at the expense of methane, maltose, sucrose, lactose, sorbitol, D-mannitol, inositol, or soluble starch. However, utilization of L-arabinose, D-xylose, D-glucose, mannose, D-fructose, galactose, trehalose, citric acid, ethanol, monomethylamine, dimethylamine, trimethylamine, TMAH, DMF, formamide, $N$-methylformamide, D-fucose, L-asparatic acid, L-glutamic acid, betaine, sebacic acid, DL-tartaric acid, pimelic acid, suberic acid, azelaic acid, and adipic acid differed among the strains (Table 2). Only strain TH-15 ${ }^{\mathrm{T}}$ utilized TMAH, formamide, $N$-methylformamide, and DMF. Oxidative production of acid from sugars was variable among the strains (Table 3). Vitamins and amino acids were not essential for the growth of all strains, and calcium pantothenate stimulated the growth of almost one-half of the strains (Table 3).

DNA base compositions. The DNA base compositions of Methylobacterium extorquens TK $0001^{\mathrm{T}}$, "Mycoplana rubra" TK 0002, Methylobacterium organophilum TK $0047^{\mathrm{T}}$, "Pseudomonas methanica" TK 0048, Methylobacterium rhodinum TK $0010^{\mathrm{T}}$, Methylobacterium rhodesianum TK $0027^{\mathrm{T}}$, "Pseudomonas rosea" TK 0012, Methylobacterium zatmanii TK $0028^{\mathrm{T}}$ and TK 0025 , strain TH- $15^{\mathrm{T}}$, Methylobacterium radiotolerans TK $0036^{\mathrm{T}}$ and TK 0035, Methylobacterium mesophilicum TK $0034^{\mathrm{T}}$, Methylobacterium fujisawaense TK $0065^{\mathrm{T}}$, and "T. rubellus" TK 0038 ranged from 68 to $72 \mathrm{~mol} \% \mathrm{G}+\mathrm{C}$ (Table 4 ).

Cellular fatty acid compositions. Methylobacterium fujisawaense TK $0065^{\mathrm{T}}$, Methylobacterium radiotolerans TK 0066 and TK 0067, and strains TK 0068 and TK 0069 contained a large amount of $\mathrm{C}_{18: 1}$ acid and small amounts of $\mathrm{C}_{16: 1}$ acid, $\mathrm{C}_{19: 0}$ cyclopropane acid, and 3-OH $\mathrm{C}_{14: 0}$ hydroxy acid. The hydroxy fatty acids included a large amount of 3-hydroxy $\mathrm{C}_{14: 0}$ acid. These cellular fatty acid compositions were as the same as the cellular fatty acid compositions of other Methylobacterium strains $(35,41,44)$.

Quinone systems. Like other Methylobacterium strains $(35,41,43)$, Methylobacterium fujisawaense TK $0065^{\mathrm{T}}$, Methylobacterium radiotolerans TK 0066 and TK 0067 , and strains TK 0068 and TK 0069 had a ubiquinone 10 system, as well as minor ubiquinone 8 , ubiquinone 9 , and ubiquinone 11 components.

Squalene and steroids. Like other Methylobacterium strains $(41,43)$, strain TH-15 ${ }^{\mathrm{T}}$, Methylobacterium fujisawaense TK $0065^{\mathrm{T}}$, Methylobacterium radiotolerans TK 0066 and TK 0067 , and strains TK 0068 and TK 0069 contained hop-22 (29)-ene and hopan-22-ol and a small amount of squalene.

Pigments. Like other Methylobacterium strains (41, 43), strain TH-15 ${ }^{\mathrm{T}}$, Methylobacterium fujisawaense TK $0065^{\mathrm{T}}$, Methylobacterium radiotolerans TK 0066 and TK 0067, and strains TK 0068 and TK 0069 contained carotenoid pigments which had absorption maxima at 465,495 , and $525 \mathrm{~nm}$ and bacteriochlorophyll $a$.

Phospholipid compositions. The phospholipids of all strains included large amounts of cardiolipin (diphosphatidylglycerol), phosphatidylethanolamine, and phosphatidylcholine and a small amount of phosphatidylglycerol (Fig. 1).

DNA-DNA hybridization. The levels of DNA relatedness among Methylobacterium strains are shown in Table 5. The strains tested were divided into seven groups (groups A through $\mathrm{G}$ ), and the similarity values between groups were less than $60 \%$. Methylobacterium extorquens TK $0001^{\mathrm{T}}$ (group A) was clearly distinguished from other Methylobacterium strains examined in this study. Methylobacterium organophilum TK $0047^{\mathrm{T}}$ (group B) and "Pseudomonas methanica" TK 0048 exhibited high level (73\%) of similarity with each other and were clearly separated from other Methylobacterium strains. Methylobacterium mesophilicum TK $0034^{\mathrm{T}}$ (group G) and "T. rubellus" TK 0038 exhibited a high level $(68 \%)$ of similarity with each other and were clearly separated from other Methylobacterium strains.

\section{DISCUSSION}

"Mycoplana rubra" TK 0002, "Protaminobacter ruber subsp. machidanus" TK 0006, TK 0007, and TK 0008, Pseudomonas sp. strains TK 0029 and TK 0037 (= Tonomura et al. K-62), "T. rubellus" TK 0038, strains TK 0040 (= ATCC 35064), TK 0042, TK 0043, TK 0044, TK 0045, TK 0068 (= NCIB 9141), TK 0069 (= NCIB 9145), and TH-15 ${ }^{\mathrm{T}}$, and "Pseudomonas methanica" TK 0067 should be included in the genus Methylobacterium on the basis of their morphological characteristics and their chemotaxonomic characteristics, including their cellular fatty acid compositions $(35,41$, $44)$, their hydroxy fatty acid compositions $(35,41,44)$, their quinone systems $(35,41,43)$, their DNA base compositions $(41,45)$, the presence of carotenoid pigments $(41)$, bacteriochlorophyll $a$ (41), squalene, and steroids [hop-22(29)-ene and hopan-22-o1] $(41,43)$, their phospholipid compositions, and the levels of DNA-DNA homology (16). Goldberg and Jensen (8) reported that the phospholipids of pink-pigmented, facultatively methylotrophic bacteria included large amounts of phosphatidylethanolamine, phosphatidylcholine, and phosphatidylglycerol and a small amount of phosphatidylglycerol. The results of these authors differed from our results in the ratio of phosphatidylglycerol to diphosphatidylglycerol. The reason for this unexpected observation is not apparent.

In 1976, the genus Methylobacterium was proposed as a new genus of rod-shaped, methane-oxidizing, facultatively methylotrophic bacteria by Patt et al. (27). This genus was established on the basis of only one strain, Methylobacterium organophilum $\mathrm{XX}^{\mathrm{T}}\left(=\mathrm{ATCC} 27886^{\mathrm{T}}\right)$, and this strain was markedly different from the members of other methaneoxidizing bacterial genera, such as the genera Methylomonas, Methylococcus, "Methylosinus," and "Methylovibrio" (47), in its ability to utilize a variety of organic substrates with carbon-carbon bonds as sources of carbon and energy. Subsequently, Methylobacterium organophilum R6 (26) and CRL-26 (17), "Methylobacterium ethanolicum" (24), and "Methylobacterium hypolimneticum (24) were described as facultatively methane-utilizing bacteria. However, lack of utilization of methane by Methylobacterium organophilum ATCC $27886^{\mathrm{T}}\left(=\right.$ TK $\left.0047^{\mathrm{T}}\right)$ was reported by Green and Bousfield (12), Romanovskaya et al. (29), and Urakami and Komagata (42). On the other hand, Hanson (14) suggested that a plasmid plays a role in the utilization of methane by Methylobacterium organophilum. Lidstrom-O'Connor et al. (23) isolated two methylotrophic bacteria, an obligately methanotrophic bacterium and a Xanthobacter species, from 
TABLE 2. Assimilation of carbon compounds by Methylobacterium strains

\begin{tabular}{|c|c|c|c|c|c|c|c|c|c|c|c|c|c|c|c|c|c|c|c|c|c|c|c|c|c|}
\hline \multirow[b]{2}{*}{ Strain } & \multirow[b]{2}{*}{ Species } & \multicolumn{24}{|c|}{ Utilization of: } \\
\hline & & & & & 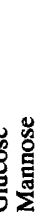 & & & 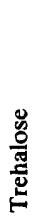 & 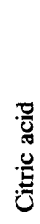 & $\begin{array}{l}\overline{0} \\
\overline{5} \\
\text { 壹 }\end{array}$ & 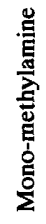 & 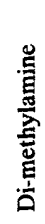 & 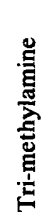 & $\sum_{i=1}^{T}$ & $\sum_{0}^{n}$ & & & 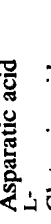 & 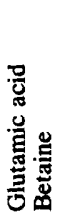 & 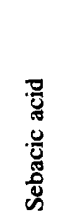 & 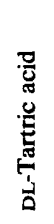 & 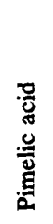 & 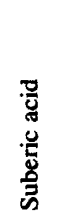 & 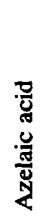 & 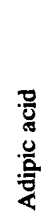 \\
\hline TK $0001^{T}$ & Methylobacterium extorquens & - & - & - & - & - & - & - & 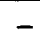 & + & $\mathrm{w}^{a}$ & - & - & - & - & - & + & + & + & - & - & - & - & - & - \\
\hline TK 0002 & & - & 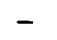 & - & - & - & - & - & - & + & + & - & - & - & - & & + & $\mathbf{w}$ & + & - & - & - & - & - & - \\
\hline TK 0003 & Methylobacterium extorquens & - & - & - & - & - & - & - & - & + & $\mathbf{w}$ & - & - & - & - & - & + & + & + & - & - & - & - & - & - \\
\hline TK 0004 & Methylobacterium extorquens & - & - & - & - & - & - & - & - & + & $\mathbf{w}$ & - & - & - & - & - & + & + & + & - & - & 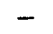 & - & - & - \\
\hline TK 0005 & Methylobacterium extorquens & - & - & - & - & - & - & - & - & + & $\mathbf{w}$ & - & - & - & - & - & + & + & -+ & - & - & - & - & - & - \\
\hline TK $0047^{\mathrm{T}}$ & Methylobacterium onganophilum & - & - & - & - & + & - & - & - & + & $\mathbf{w}$ & - & + & - & - & - & $w$ & $\mathbf{w}$ & - & - & - & - & - & _- & - \\
\hline TK 0048 & & - & - & - & - & + & - & - & - & + & $\mathbf{w}$ & - & + & - & - & - & + & $\mathbf{w}$ & $\mathrm{w}$ & - & - & - & - & - & - \\
\hline TK $0010^{T}$ & Methylobacterium rhodinum & - & - & - & - & + & - & - & + & + & $\mathbf{w}$ & - & - & - & - & - & + & $\mathbf{w}$ & + & - & $\mathbf{w}$ & - & - & - & - \\
\hline TK 0069 & & - & - & - & - & + & - & - & + & $\mathbf{w}$ & $\mathbf{w}$ & - & - & - & - & - & $\mathbf{w}$ & $\mathbf{w}$ & + & - & $\mathbf{w}$ & - & - & - & - \\
\hline TK $0027^{\mathrm{T}}$ & Methylobacterium rhodesianum & - & - & - & - & + & - & - & - & $\mathbf{w}$ & + & + & - & - & - & - & w & $\mathbf{w}$ & w & - & $\mathbf{w}$ & - & - & - & - \\
\hline TK 0006 & & - & - & - & - & + & - & - & - & + & + & - & - & - & - & - & + & + & + & - & $\mathbf{w}$ & - & - & - & - \\
\hline TK 0 & & - & - & - & - & + & - & - & - & + & + & - & - & - & - & - & + & + & -+ & - & $\mathbf{w}$ & - & - & - & 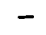 \\
\hline TK 0 & & - & - & - & - & + & - & - & - & + & + & - & - & - & - & - & + & $\mathbf{w}$ & - & - & - & - & - & - & 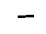 \\
\hline TK 0009 & Methylobacterium rhodesianum & - & - & - & - & + & - & - & - & + & + & - & - & - & - & - & + & $\mathbf{w}$ & + & - & - & - & - & - & - \\
\hline TK 0012 & Methylobacterium rhodesianum & - & - & - & - & + & - & - & - & + & $\mathbf{w}$ & + & - & - & - & - & + & + & + & - & - & - & - & - & - \\
\hline TK 0013 & Methylobacterium rhodesianum & - & - & - & - & + & - & - & - & + & w & + & - & - & - & - & + & + & + & - & - & - & - & - & - \\
\hline TK 0 & bacterium rhodesianum & - & - & - & - & + & - & - & - & + & $\mathbf{w}$ & + & - & - & - & - & + & + & -+ & - & - & - & - & - & - \\
\hline TK 0015 & acterium rhodesianum & - & - & - & - & + & - & - & - & + & $\mathbf{w}$ & + & - & - & - & - & + & + & -+ & - & - & - & - & - & - \\
\hline TK 0016 & cterium rho & - & - & - & - & + & - & - & - & + & w & + & - & - & - & - & + & + & + & - & - & - & - & - & - \\
\hline TK 0017 & Methylobacterium rhodesianum & - & - & - & - & + & - & - & - & + & $\mathbf{w}$ & + & - & - & - & - & + & + & + & - & - & - & - & - & - \\
\hline TK 0029 & & - & - & - & 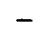 & + & - & - & - & + & $\mathbf{w}$ & - & - & - & - & - & + & + & -+ & - & $\mathbf{w}$ & - & - & - & - \\
\hline TK 0 & & - & - & - & - & + & - & - & - & $\mathbf{w}$ & + & - & - & - & - & - & $\mathbf{w}$ & $\mathbf{w}$ & + & - & $\mathbf{w}$ & - & - & - & \\
\hline TK $0028^{T}$ & um zatmanii & - & - & - & - & + & - & - & - & + & + & - & + & - & - & - & - & - & - & - & $\mathbf{w}$ & - & - & - & - \\
\hline TK 0018 & acterium $z$ & - & - & - & - & + & - & - & - & + & $\mathbf{w}$ & - & + & - & - & - & - & - & - & - & $\mathbf{w}$ & - & - & - & - \\
\hline TK 0 & acterium zatmanii & - & - & - & - & + & - & - & - & + & $\mathrm{v}$ & - & + & - & - & - & - & - & - & - & $\mathbf{w}$ & - & - & - & - \\
\hline TK 0020 & cterium zat & - & - & - & - & + & - & - & - & + & $\mathbf{w}$ & - & + & - & - & - & - & - & - & - & $\mathbf{w}$ & - & - & - & - \\
\hline TK 0021 & acterium zatmanii & - & - & - & - & + & - & - & - & + & $\mathbf{w}$ & - & + & - & - & - & - & - & $=-$ & - & $\mathbf{w}$ & - & - & - & - \\
\hline TK 0022 & bacterium zatmanii & - & - & - & - & + & - & - & - & + & w & - & + & - & - & - & - & - & - & - & $\mathbf{w}$ & - & - & - & - \\
\hline TK 0023 & acterium zatmanii & - & - & - & - & + & - & - & - & + & $\mathrm{v}$ & - & + & - & - & - & - & - & - & - & v & - & - & - & - \\
\hline TK 0024 & $m$ zatmanii & - & - & - & - & + & - & - & - & + & $\mathrm{v}$ & - & + & - & - & - & - & - & - & - & $\mathbf{w}$ & - & - & - & 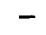 \\
\hline TK 0025 & Methylobacterium zatmanii & - & - & - & - & + & - & - & - & + & $\mathbf{w}$ & - & + & - & - & - & - & - & - & - & $\mathbf{w}$ & - & - & - & - \\
\hline $\mathrm{TH}-15^{\mathrm{T}}$ & & - & - & - & - & + & - & - & - & + & + & + & + & + & + & + & + & w & + & - & $\mathbf{w}$ & - & - & - & \\
\hline TK $0036^{\mathrm{T}}$ & liotolerans & + & + & + & - & - & + & - & + & $\mathbf{w}$ & - & - & - & - & - & + & $\mathbf{w}$ & + & + & + & $\mathbf{w}$ & + & + & + & \\
\hline TK 0035 & diotolerans & + & $\mathbf{w}$ & + & - & - & + & - & + & $\mathbf{w}$ & - & - & - & - & - & + & + & + & -+ & + & 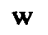 & + & + & + & $\mathbf{w}$ \\
\hline TK 0066 & diatorans & + & + & + & - & - & $\mathbf{w}$ & - & + & - & - & - & - & - & - & + & $\mathbf{w}$ & + & -+ & + & $\mathbf{w}$ & + & + & + & \\
\hline TK 0067 & terium radiotolerans & + & + & + & - & - & + & - & + & - & - & - & - & - & - & + & $\mathbf{w}$ & + & + & + & $\mathbf{w}$ & + & + & + & \\
\hline TK $0034^{T}$ & Methylobacterium mesophilicum & + & $\mathbf{w}$ & + & - & - & + & - & + & $\mathbf{w}$ & - & - & - & - & - & $\mathbf{w}$ & $\mathbf{w}$ & + & - - & + & - & $\mathbf{w}$ & + & $\mathbf{w}$ & $\mathbf{w}$ \\
\hline TK $0065^{\mathrm{T}}$ & Methylobacterium fujisawaense & + & + & + & - & - & + & - & + & + & - & - & - & - & - & + & $\mathbf{w}$ & + & - & + & - & + & + & + & $\mathbf{w}$ \\
\hline TK 0039 & im fujisawaense & $\mathbf{w}$ & $\mathbf{w}$ & + & - & - & + & - & + & $\mathbf{w}$ & - & - & - & - & - & + & + & + & - & + & - & + & + & + & + \\
\hline TK 0042 & & $\mathbf{w}$ & $\mathbf{w}$ & + & $\mathbf{w}$ & - & + & - & + & - & - & - & - & - & - & + & + & + & - & + & - & + & + & + & \\
\hline TK 0043 & & $\mathbf{w}$ & + & + & - & - & + & $\mathbf{w}$ & w & $\mathrm{n}$ & - & - & - & - & - & + & + & + & - & + & $\mathbf{w}$ & + & + & + & $\mathbf{w}$ \\
\hline TK 0 & & + & $\mathbf{w}$ & $w$ & - & + & + & - & & $\mathbf{w}$ & - & - & - & - & - & + & - & + & - & $\mathbf{w}$ & - & $\mathbf{w}$ & + & $w$ & + \\
\hline TK 0037 & & + & + & + & - & + & + & $\mathbf{w}$ & + & - & - & - & - & - & - & + & - & + & - & + & - & + & + & + & $\mathbf{w}$ \\
\hline TK 0040 & & + & + & + & - & + & + & - & + & $\mathbf{w}$ & - & - & - & - & - & + & + & + & + & + & - & + & + & + & $\mathbf{w}$ \\
\hline TK 00 & & $\mathbf{w}$ & + & + & - & + & + & 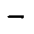 & + & - & - & - & - & - & - & + & $\mathbf{w}$ & + & - & + & - & + & + & + & + \\
\hline TK 0045 & & $\mathbf{w}$ & + & + & $\mathbf{w}$ & $\mathbf{w}$ & + & - & + & - & - & - & - & - & - & + & $\mathbf{w}$ & + & - & + & - & + & + & + & + \\
\hline
\end{tabular}

${ }^{a}$, weak. 
TABLE 3. Oxidative production of acid from sugars and vitamin requirements of Methylobacterium strains

\begin{tabular}{|c|c|c|c|c|c|c|c|c|c|}
\hline \multirow[b]{2}{*}{ Strain } & \multirow[b]{2}{*}{ Species } & \multicolumn{7}{|c|}{ Oxidation of: } & \multirow{2}{*}{$\begin{array}{c}\text { Requirement } \\
\text { for calcium } \\
\text { pantothenate } \\
\text { as a } \\
\text { stimulate }\end{array}$} \\
\hline & & 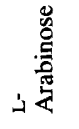 & 若 & 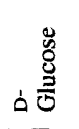 & 兽 & 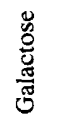 & $\begin{array}{l}\overline{0} \\
\stackrel{0}{0} \\
\frac{2}{0}\end{array}$ & 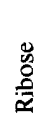 & \\
\hline TK $0001^{T}$ & Methylobacterium extorquens & $\mathbf{w}^{a}$ & w & - & - & - & + & $\mathbf{w}$ & - \\
\hline TK 0002 & & $\mathbf{w}$ & w & - & - & - & + & $\mathbf{w}$ & - \\
\hline TK 0003 & Methylobacterium extorquens & $\mathbf{w}$ & $\mathbf{w}$ & - & - & - & + & $\mathbf{w}$ & - \\
\hline TK 0004 & Methylobacterium extorquens & $\mathbf{w}$ & w & - & - & - & + & $\mathbf{w}$ & - \\
\hline TK 0005 & Methylobacterium extorquens & $\mathbf{w}$ & $\mathbf{w}$ & - & - & - & + & $\mathbf{w}$ & - \\
\hline TK $0047^{\mathrm{T}}$ & Methylobacterium organophilum & w & $\mathbf{w}$ & $\mathbf{w}$ & $\mathbf{w}$ & - & + & $\mathbf{w}$ & - \\
\hline TK 0048 & & $\mathbf{w}$ & w & $\mathbf{w}$ & $\mathbf{w}$ & - & + & w & - \\
\hline TK $0010^{T}$ & Methylobacterium rhodinum & $\mathbf{w}$ & w & - & - & - & + & $\mathbf{w}$ & - \\
\hline TK 0069 & & $\mathbf{w}$ & $\mathbf{w}$ & - & $\mathbf{w}$ & - & + & $\mathbf{w}$ & - \\
\hline TK $0027^{\mathrm{T}}$ & Methylobacterium rhodesianum & $\mathbf{w}$ & w & - & + & - & + & $\mathbf{w}$ & - \\
\hline TK 0006 & & $\mathbf{w}$ & + & - & $\mathbf{w}$ & - & + & $\mathbf{w}$ & - \\
\hline TK 0007 & & $\mathbf{w}$ & $\mathbf{w}$ & - & $\mathbf{w}$ & - & + & $\mathbf{w}$ & - \\
\hline TK 0008 & & $\mathbf{w}$ & + & - & $\mathbf{w}$ & - & + & $\mathbf{w}$ & - \\
\hline TK 0009 & Methylobacterium rhodesianum & $\mathbf{w}$ & + & - & $\mathbf{w}$ & - & + & $\mathbf{w}$ & - \\
\hline TK 0012 & Methylobacterium rhodesianum & $\mathbf{w}$ & + & - & $\mathbf{w}$ & - & + & w & - \\
\hline TK 0013 & Methylobacterium rhodesianum & $\mathbf{w}$ & + & - & $\mathbf{w}$ & - & + & $\mathbf{w}$ & - \\
\hline TK 0014 & Methylobacterium rhodesianum & $\mathbf{w}$ & $\mathbf{w}$ & - & $\mathbf{w}$ & - & + & $\mathbf{w}$ & - \\
\hline TK 0015 & Methylobacterium rhodesianum & $\mathbf{w}$ & + & - & $\mathbf{w}$ & - & + & $\mathbf{w}$ & - \\
\hline TK 0016 & Methylobacterium rhodesianum & $\mathbf{w}$ & $\mathbf{w}$ & - & $\mathbf{w}$ & - & + & w & - \\
\hline TK 0017 & Methylobacterium rhodesianum & $\mathbf{w}$ & $\mathbf{w}$ & - & $\mathbf{w}$ & - & + & $\mathbf{w}$ & - \\
\hline TK 0029 & & $\mathbf{w}$ & $\mathbf{w}$ & - & $\mathbf{w}$ & - & $\mathbf{w}$ & $\mathbf{w}$ & - \\
\hline TK 0068 & & $\mathbf{w}$ & + & - & $\mathbf{w}$ & - & + & w & - \\
\hline TK $0028^{\mathrm{T}}$ & Methylobacterium zatmanii & $\mathbf{w}$ & + & - & $\mathbf{w}$ & - & + & $\mathbf{w}$ & - \\
\hline TK 0018 & Methylobacterium zatmanii & w & + & - & w & - & + & $w$ & - \\
\hline TK 0019 & Methylobacterium zatmanii & $\mathbf{w}$ & + & - & $\mathbf{w}$ & - & + & $\mathbf{w}$ & - \\
\hline TK 0020 & Methylobacterium zatmanii & $\mathbf{w}$ & + & - & $\mathbf{w}$ & - & + & $\mathbf{w}$ & - \\
\hline TK 0021 & Methylobacterium zatmanii & w & + & - & $\mathbf{w}$ & - & + & $\mathbf{w}$ & - \\
\hline TK 0022 & Methylobacterium zatmanii & $\mathbf{w}$ & + & - & $\mathbf{w}$ & - & + & $\mathbf{w}$ & - \\
\hline TK 0023 & Methylobacterium zatmanii & $\mathbf{w}$ & + & - & $\mathbf{w}$ & - & + & $\mathbf{w}$ & - \\
\hline TK 0024 & Methylobacterium zatmanii & $\mathbf{w}$ & + & - & $\mathbf{w}$ & - & + & $\mathbf{w}$ & - \\
\hline TK 0025 & Methylobacterium zatmanii & $\mathbf{w}$ & + & - & w & - & + & w & - \\
\hline TH- $15^{\mathrm{T}}$ & & $\mathbf{w}$ & $\mathbf{w}$ & - & $\mathbf{w}$ & - & + & w & - \\
\hline TK $0036^{\mathrm{T}}$ & Methylobacterium radiotolerans & - & - & - & - & - & - & - & + \\
\hline TK 0035 & Methylobacterium radiotolerans & - & - & - & - & - & + & $\mathbf{w}$ & + \\
\hline TK 0066 & Methylobacterium radiotolerans & + & $\mathbf{w}$ & - & - & + & + & $\mathbf{w}$ & + \\
\hline TK 0067 & Methylobacterium radiotolerans & + & - & - & - & + & - & $\mathbf{w}$ & + \\
\hline TK $0034^{\mathrm{T}}$ & Methylobacterium mesophilicum & - & $\mathbf{w}$ & - & - & - & - & - & + \\
\hline TK $0065^{\mathrm{T}}$ & Methylobacterium fujisawaense & $\mathbf{w}$ & $\mathbf{w}$ & - & - & - & - & - & + \\
\hline TK 0039 & Methylobacterium fujisawaense & + & + & - & - & + & + & - & + \\
\hline TK 0042 & & + & + & - & - & - & + & $\mathbf{w}$ & + \\
\hline TK 0043 & & - & + & - & - & - & - & - & + \\
\hline TK 0038 & & - & + & - & - & - & + & $\mathbf{w}$ & + \\
\hline TK 0037 & & + & + & - & $\mathbf{w}$ & + & $\mathbf{w}$ & + & + \\
\hline TK 0040 & & $\mathbf{w}$ & $\mathbf{w}$ & - & $w$ & - & + & - & + \\
\hline TK 0044 & & + & + & - & - & + & - & $\mathbf{w}$ & + \\
\hline TK 0045 & & + & + & - & - & + & - & $\mathbf{w}$ & + \\
\hline
\end{tabular}

${ }^{a} \mathrm{w}$, weak.

cultures of "Methylobacterium ethanolicum" which were grown in methane. Therefore, at present the existence of facultatively methanotrophic bacteria is questionable.

In 1983, Green and Bousfield (12) proposed emendation of the genus Methylobacterium description to permit inclusion of pink-pigmented, non-methane-utilizing, facultatively methylotrophic bacteria and described four species, Methylobacterium organophilum, Methylobacterium rhodinum, Methylobacterium radiotolerans, and Methylobacterium mesophilicum. Furthermore, in 1985 Bousfield and Green (4) proposed reclassification of the genus Protomonas Urakami and Komagata 1984 and transfer of Protomonas extorquens to the genus Methylobacterium (Patt, Cole, and Hanson) emend. Green and Bousfield 1983. Protomonas extorquens was reclassified as Methylobacterium extorquens. Although the utilization of methane by Methylobacterium strains was not confirmed by these authors, their emended description of the genus Methylobacterium did not exclude methane-utilizing bacteria (12). The utilization of methane is a very important characteristics of the genus Methylobacterium as established by Patt et al. (27); therefore, nonutilization of methane should be mentioned in the description of the genus Methylobacterium. Furthermore, DNA base compositions ranging from 60 to $70 \mathrm{~mol} \% \mathrm{G}+\mathrm{C}$ show that the genus is heterogeneous. Hood et al. (16) studied the DNA base compositions of Methylobacterium strains by using the 
TABLE 4. DNA base compositions of Methylobacterium strains

\begin{tabular}{|c|c|c|c|c|c|}
\hline \multirow{3}{*}{ Strain } & \multirow{3}{*}{ Species } & \multicolumn{4}{|c|}{$\mathrm{G}+\mathrm{C}$ content $(\mathrm{mol} \%)$} \\
\hline & & \multirow[b]{2}{*}{ This study ${ }^{a}$} & \multicolumn{2}{|c|}{ Study of Hood et al. ${ }^{b}$} & \multirow[b]{2}{*}{ Other studies ${ }^{c}$} \\
\hline & & & $\begin{array}{l}\text { Buoyant density } \\
\text { method }\end{array}$ & $\begin{array}{l}\text { Thermal } \\
\text { denaturation method }\end{array}$ & \\
\hline $\begin{array}{l}\text { TK } 0001^{\mathrm{T}} \\
\text { TK } 0002\end{array}$ & Methylobacterium extorquens & $\begin{array}{l}68.2 \\
68.3\end{array}$ & 69.4 & & $65.6\left(T_{m}\right)$ \\
\hline TK 0003 & & & 68.8 & 69.1 & $65.6\left(T_{m}\right)$ \\
\hline TK $0047^{\mathrm{T}}$ & Methylobacterium organophilum & 70.5 & 71.1 & 70.5 & $66.8\left(T_{m}^{m}\right), 66.0(\mathrm{BD})$ \\
\hline TK 0048 & & 69.2 & & & $66.0\left(T_{m}\right)$ \\
\hline TK $0010^{\mathrm{T}}$ & Methylobacterium rhodinum & 70.2 & 71.8 & & $65.8\left(T_{m}\right)$ \\
\hline $\begin{array}{l}\text { TK } 0027^{\mathrm{T}} \\
\text { TK } 0012\end{array}$ & Methylobacterium rhodesianum & $\begin{array}{l}68.9 \\
69.2\end{array}$ & & & \\
\hline TK 0016 & & & 70.9 & & $65.4\left(T_{m}\right)$ \\
\hline TK $0028^{\mathrm{T}}$ & Methylobacterium zatmanii & 68.8 & 70.3 & & $66.1\left(T_{m}\right)$ \\
\hline $\begin{array}{l}\text { TK } 0025 \\
\text { TH }-15^{\mathrm{T}}\end{array}$ & & 69.3 & & & $66.1\left(T_{m}\right)$ \\
\hline $\mathrm{TH}-15^{\mathrm{T}}$ & & 68.0 & & & \\
\hline TK $0036^{\mathrm{T}}$ & Methylobacterium radiotolerans & 71.2 & 72.3 & & $65.9\left(T_{m}\right)$ \\
\hline TK 0035 & & 70.9 & & & $65.8\left(T_{m}\right)$ \\
\hline TK $0034^{T}$ & Methylobacterium mesophilicum & 69.5 & 69.9 & & $66.0\left(T_{m}\right), 65.8\left(T_{m}\right)$ \\
\hline TK $0065^{\mathrm{T}}$ & Methylobacterium fujisawaense & 69.9 & 71.8 & & \\
\hline TK 0038 & & 69.5 & & & $65.0,65.4\left(T_{m}\right)$ \\
\hline
\end{tabular}

a $\mathrm{G}+\mathrm{C}$ contents were determined by reverse-phase HPLC.

${ }^{b}$ Data from reference 16 .

c Data from references $2,18,25,26$, and 45 . The values were determined by the thermal denaturation method ( $\left.T_{m}\right)$ or the buoyant density method (BD).

buoyant density and thermal denaturation methods, but their values were approximately $5 \mathrm{~mol} \%$ higher than the values determined by other researchers $(2,18,25,27,45)$, as shown in Table 4. In this study, the DNA base compositions determined by the HPLC method nearly coincided with the values determined by Hood et al. As determined in this study, the DNA base compositions of the genus Methylobacterium strains are 68 to $72 \mathrm{~mol} \%$. In the recently published second edition of The Prokaryotes (10), Green states that the DNA base compositions of members of the genus Methylobacterium range from 68.4 to $72.4 \mathrm{~mol} \% \mathrm{G}+\mathrm{C}$.

Recently, a genotypic study of Methylobacterium strains was carried out. Wolfrum et al. (48) reported the levels of nucleic acid hybridization for bacteria belonging to the genera Methylobacterium and Pseudomonas. Furthermore, the 5S rRNA sequences of Methylobacterium extorquens TK $0001^{\mathrm{T}}$ (21), Methylobacterium extorquens TK 0004 (6), and Methylobacterium organophilum TK $0047^{\mathrm{T}}$ (6) were determined, and the phylogenetic diversity of methanolutilizing bacteria was discussed by Ando et al. (1). The 16S rRNA sequences of methylotrophic bacteria, including $M e$ thylobacterium extorquens and Methylobacterium organophilum $(5,34)$, have been determined. On the basis of these studies, Methylobacterium strains were clearly distinguished from other methylotrophic bacteria (strains belonging to the genera Methylobacillus, Methylophilus, Hyphomicrobium, Ancylobacter, and Paracoccus), methanotrophic bacteria (strains belonging to the genera Methylomonas and Methylococcus), and Pseudomonas strains.

Methylobacterium strains were divided into eight species on the basis of utilization of carbon compounds, and this grouping was supported by electrophoretic enzyme type (40) and DNA-DNA homology data (Table 5). Group 1 contained Methylobacterium extorquens, group 2 contained Methylobacterium onganophilum, group 3 contained Methylobacterium rhodinum, group 4 contained Methylobacterium rhodesianum, group 5 contained Methylobacterium zatmanii, group 6 contained strain TH-15 ${ }^{\mathrm{T}}$, and group 7 contained
Methylobacterium radiotolerans. Group 8 contained Methylobacterium fujisawaense, Methylobacterium mesophilicum, Pseudomonas sp. strain TK 0037, "T. rubellus" TK 0038, and strains TK 0040 (= ATCC 35064), TK 0042, TK 0043, TK 0044, and TK 0045. Methylobacterium mesophilicum and Methylobacterium fujisawaense, which were distinguished from each other on the basis of DNA-DNA homology data (15) (Table 6), were not distinguished from each other on the basis of phenotypic characteristics. Green et al. (13) have described differences between Methylobacterium mesophilicum and Methylobacterium fujisawaense in the ability to utilize D-fructose and acetate as sole carbon sources and in the ability to grown on peptone-rich media. However, the difference between these two species was not confirmed in this study. Therefore, strains TK 0037, TK 0038, TK 0040, TK 0042, TK 0043, and TK 0044 were not identified in this study. From the data which we obtained and from practical considerations of identification, we believe that these two species should be characterized more precisely in the future insofar as this is possible.

The minimal characteristics for differentiating species in the genus Methylobacterium are shown in Table 6. However, the utilization of D-glucose by Methylobacterium rhodinum and Methylobacterium organophilum differs from the results of Green (10) and Green et al. (13). The reason for this unexpected observation is not apparent. The levels of DNA-DNA homology between strain TH-15 ${ }^{\mathrm{T}}$ and the other Methylobacterium strains examined (28 to $56 \%$ ) suggest that strain $\mathrm{TH}-15^{\mathrm{T}}$ may represent a new species. In addition, strain $\mathrm{TH}-15^{\mathrm{T}}$ was the only organism examined in this study which could utilize TMAH and DMF as sole carbon sources (Table 6). Therefore, we believe that strain TH-15 ${ }^{\mathrm{T}}$ should be separated from other methylobacteria at the species level; consequently, we propose a new species, Methylobacterium aminovorans, for this strain. The differential characteristics of Methylobacterium species are shown in Table 7.

On the basis of our data and the data in a previous report (41), "Pseudomonas methanica" TK 0048 (= NRRL 


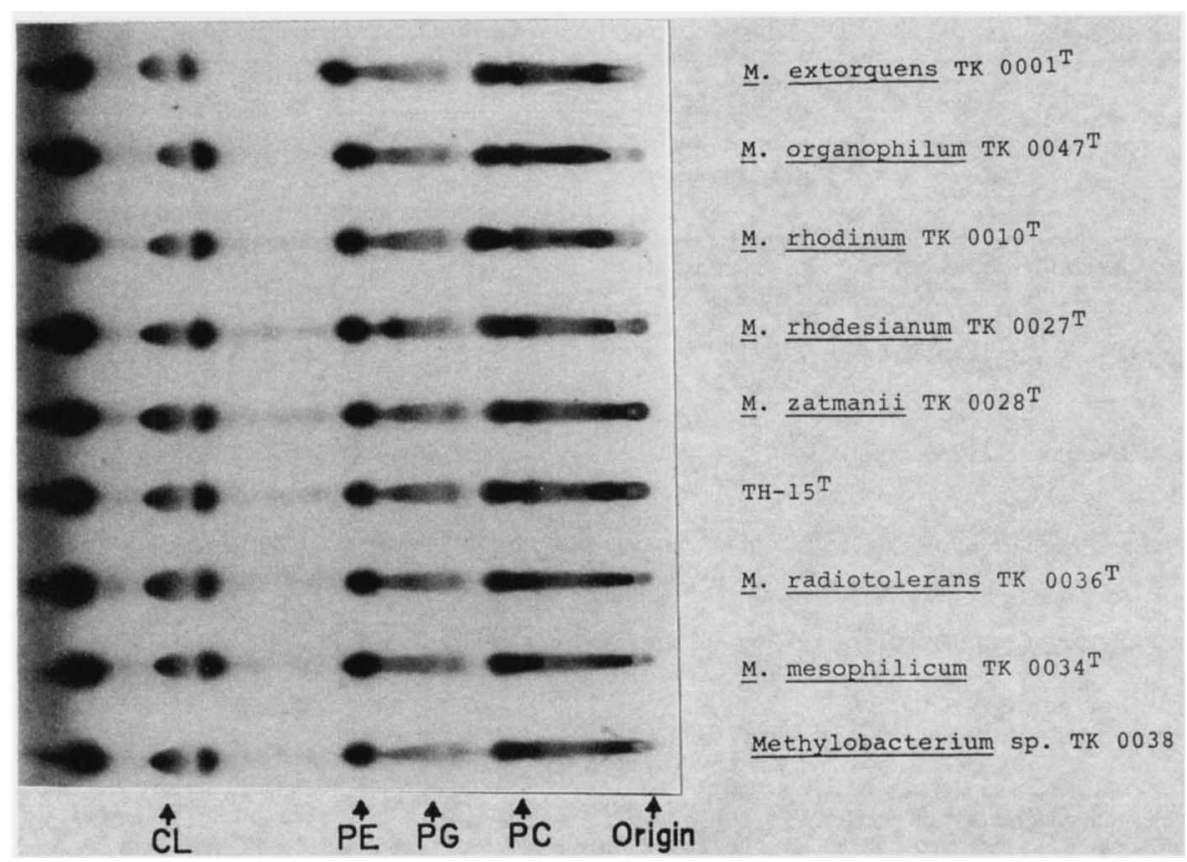

FIG. 1. Thin-layer chromatographic patterns of lipids of Methylobacterium strains. CL, cardiolipin; PE, phosphatidylethanolamine; PG, phosphatidylglycerol; PC, phosphatidylcholine.

B-3449) should be identified as a strain of Methylobacterium onganophilum; "Mycoplana rubra" TK 0002, "Protaminobacter ruber" TK 0003, Pseudomonas sp. strain TK 0004 (= AM 1), and Pseudomonas sp. strain TK 0005 (= M27), which were included in Protomonas extorquens biovar 1 (41), should be identified as strains of Methylobacterium extorquens; strain TK 0069 should be identified as a strain of Methylobacterium rhodinum; "Protaminobacter ruber subsp. machidanus" TK 0006, TK 0007, TK 0008, and TK 0009, "Pseudomonas rosea" TK 0012, TK 0013, TK 0014, TK 0015, TK 0016, and TK 0017, Pseudomonas sp. strain TK 0029, and strain TK 0068 should be identified as strains of Methylobacterium rhodesianum; and "Pseudomonas rosea" TK 0018, TK 0019, TK 0020, TK 0021, TK 0022, TK 0023, TK 0024, and TK 0025 should be included in Methylobacterium zatmanii. The taxonomic positions of Pseudomonas sp. strain TK 0037, "T. rubellus" TK 0038, and strains TK 0040 (= ATCC 35064), TK 0042, TK 0043, TK 0044, and TK 0045 were not determined in this study, but these bacteria may be members of Methylobacterium mesophilicum or Methylobacterium fujisawaense.
Description of Methylobacterium aminovorans Urakami, Araki, Suzuki, and Komagata sp. nov. Methylobacterium aminovorans (a.mi.no'vo.rans. N.L.n aminus, amine; L. part.adj. vorans, devouring, digesting; N.L.part.adj. aminovorans, amine digesting) cells are non-spore-forming, gramnegative rods that are 0.8 to 1.0 by 1.5 to $4.0 \mu \mathrm{m}$ and have rounded ends. Cells occur singly or rarely in pairs. Cells are motile by means of a single polar flagellum. Some cells have a subpolar or lateral flagellum. Granules of poly- $\beta$-hydroxybutyric acid accumulate in the cells. Colonies on glucoseyeast extract-peptone agar are shiny, smooth, raised, entire, pink or red, and 1 to $3 \mathrm{~mm}$ in diameter after 5 days at $30^{\circ} \mathrm{C}$. Lighter pink colonies appear frequently, and colorless colonies appear rarely. The red or pink pigment is a carotenoid pigment, and absorption maxima occur at 465,495 , and 525 $\mathrm{nm}$. Bacteriochlorophyll $a$ is formed under specific culture conditions.

Nitrate is reduced to nitrite. Methyl red and VogesProskauer tests are negative. Indole and hydrogen sulfide are not produced. Hydrolysis of gelatin and starch is not observed. Ammonia is not produced. Acid is produced oxida-

TABLE 5. Levels of DNA-DNA homology of Methylobacterium strains

\begin{tabular}{|c|c|c|c|c|c|c|c|}
\hline \multirow{2}{*}{ Strain } & \multirow{2}{*}{ Species } & \multicolumn{5}{|c|}{ \% DNA-DNA homology with strain: } & \multirow{2}{*}{$\begin{array}{c}\text { DNA-DNA } \\
\text { homology } \\
\text { group }\end{array}$} \\
\hline & & TK $0001^{\mathrm{T}}$ & TK $0047^{\mathrm{T}}$ & TK $0010^{\mathrm{T}}$ & $\mathrm{TH}-15^{\mathrm{T}}$ & TK $0034^{\mathrm{T}}$ & \\
\hline TK 0001 & Methylobacterium extorquens & 100 & 23 & 45 & 40 & 30 & $\mathbf{A}$ \\
\hline TK $0047^{\mathrm{T}}$ & Methylobacterium organophilum & 31 & 100 & 36 & 32 & 36 & B \\
\hline TK 0048 & & 27 & 73 & 48 & 36 & 36 & $\mathbf{B}$ \\
\hline TK $0010^{\mathrm{T}}$ & Methylobacterium rhodinum & 18 & 30 & 100 & 53 & 18 & $\mathrm{C}$ \\
\hline TK 0025 & Methylobacterium zatmanii & 46 & 33 & 57 & 56 & 49 & $\mathrm{D}$ \\
\hline $\mathrm{TH}-15^{\mathrm{T}}$ & & 47 & 30 & 55 & 100 & 43 & $\mathbf{E}$ \\
\hline TK $0036^{\mathrm{T}}$ & Methylobacterium radiotolerans & 24 & 24 & 39 & 31 & 55 & $\mathbf{F}$ \\
\hline TK $0034^{T}$ & Methylobacterium mesophilicum & 17 & 17 & 12 & 30 & 100 & $\mathrm{G}$ \\
\hline TK 0038 & & 24 & 26 & 40 & 28 & 68 & $\mathbf{G}$ \\
\hline
\end{tabular}


TABLE 6. Grouping of Methylobacterium strains based on assimilation type, electrophoretic type, and DNA-DNA homology type

\begin{tabular}{|c|c|c|c|c|c|}
\hline \multirow{2}{*}{$\begin{array}{l}\text { Assimilation } \\
\text { group }\end{array}$} & \multirow{2}{*}{ Species } & \multirow{2}{*}{ Strain(s) } & \multirow{2}{*}{$\begin{array}{c}\text { Electrophoretic } \\
\text { type } \\
\text { (subgroup) }^{a}\end{array}$} & \multicolumn{2}{|c|}{$\begin{array}{l}\text { DNA-DNA homology } \\
\text { group }\end{array}$} \\
\hline & & & & This study & $\begin{array}{c}\text { Study of } \\
\text { Hood et al. }\end{array}$ \\
\hline 1 & Methylobacterium extorquens & $\begin{array}{l}\text { TK } 0001^{\mathrm{T}} \\
\text { TK } 0002-\text { TK } 0005\end{array}$ & $\begin{array}{l}1 \\
1\end{array}$ & $\mathbf{A}$ & 1B \\
\hline 2 & Methylobacterium organophilum & $\begin{array}{l}\text { TK } 0047^{\mathrm{T}} \\
\text { TK } 0048\end{array}$ & & $\begin{array}{l}\mathbf{B} \\
\mathbf{B}\end{array}$ & $1 H$ \\
\hline 3 & Methylobacterium rhodinum & $\begin{array}{l}\text { TK } 0010^{\mathrm{T}} \\
\text { TK } 0069\end{array}$ & & $\mathrm{C}$ & $1 G$ \\
\hline 4 & Methylobacterium rhodesianum & $\begin{array}{l}\text { TK } 0027^{\text {T }} \\
\text { TK } 0006-\text { TK } 0009 \text {, TK 0012-TK 0017, TK } 0029 \\
\text { TK } 0068\end{array}$ & $\begin{array}{l}3 \\
3\end{array}$ & & $1 \mathrm{C}$ \\
\hline 5 & Methylobacterium zatmanii & $\begin{array}{l}\text { TK } 0028^{\mathrm{T}} \\
\text { TK } 0025 \\
\text { TK } 0018-\text { TK } 0024\end{array}$ & $\begin{array}{l}2 \\
2 \\
2\end{array}$ & D & $1 \mathrm{~A}$ \\
\hline 6 & & TH- $15^{\mathrm{T}}$ & & $\mathbf{E}$ & \\
\hline 7 & Methylobacterium radiotolerans & $\begin{array}{l}\text { TK } 0036^{\mathrm{T}} \\
\text { TK } 0035 \\
\text { TK } 0066 \\
\text { TK } 0067\end{array}$ & $\begin{array}{l}4 \\
4\end{array}$ & F & $\begin{array}{l}2 B \\
2 B\end{array}$ \\
\hline 8 & $\begin{array}{l}\text { Methylobacterium mesophilicum } \\
\text { Methylobacterium fujisawaense }\end{array}$ & $\begin{array}{l}\text { TK } 0034^{\mathrm{T}} \\
\text { TK } 0065^{\mathrm{T}}\end{array}$ & 4 & G & $\begin{array}{l}2 \mathrm{E} \\
2 \mathrm{D}\end{array}$ \\
\hline & Methylobacterium sp. & TK 0042 , TK 0043 & 4 & & \\
\hline & Methylobacterium sp. & $\begin{array}{l}\text { TK } 0038 \\
\text { TK } 0037 \text { TK } 0040 . \text { TK } 0044 . \text { TK } 0045\end{array}$ & $\begin{array}{l}4 \\
4\end{array}$ & G & \\
\hline
\end{tabular}

\footnotetext{
${ }^{a}$ Data from reference 40.

$b$ Data from reference 16 .
}

tively from glycerol, but is not produced from D-glucose or galactose. Methanol, D-fructose, glycerol, ethanol, monomethylamine, dimethylamine, trimethylamine, TMAH, formamide, $N$-methylformamide, DMF, succinic acid, L-asparatic acid, L-glutamic acid, and betain are utilized, but $\mathrm{L}$-arabinose, D-xylose, D-glucose, mannose, galactose, trehalose, maltose, sucrose, lactose, D-sorbitol, D-mannitol, inositol, soluble starch, citric acid, D-fucose, sebacic acid, DL-tartaric acid, pimelic acid, suberic acid, azelaic acid, adipic acid, hydrogen, and methane are not utilized. Growth factors are not required. Ammonia, nitrate, and urea are assimilated as nitrogen sources. Urease, oxidase, and cata- lase are produced. Aerobic. Metabolism is strictly respiratory and not fermentative.

Good growth occurs between $\mathrm{pH} 6.0$ and 8.0 and at $30^{\circ} \mathrm{C}$. Growth does not occur in the presence of $3 \%$ sodium chloride. The DNA base composition is $68.0 \mathrm{~mol} \% \mathrm{G}+\mathrm{C}$. The cellular fatty acids include a large amount of octadecenoic $\left(\mathrm{C}_{18: 1}\right)$ acid. The major hydroxy fatty acid is 3-hydroxy $\mathrm{C}_{\text {14:0 }}$ acid. The phospholipids include large amounts of cardiolipin, phosphatidylethanolamine, and phosphatidylcholine. The ubiquinone system is ubiquinone 10 . Methanol is utilized by the serine pathway with formaldehyde incor-

TABLE 7. Differential characteristics of Methylobacterium species

\begin{tabular}{|c|c|c|c|c|c|c|c|c|c|c|c|c|c|c|c|c|c|c|c|c|}
\hline \multirow[b]{2}{*}{ Species or strain(s) } & \multicolumn{19}{|c|}{ Utilization of: } & \multirow[b]{2}{*}{$\begin{array}{c}\text { Requirement } \\
\text { for calcium } \\
\text { pantothenate } \\
\text { as a } \\
\text { stimulate }\end{array}$} \\
\hline & 总 & 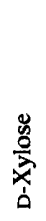 & 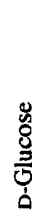 & 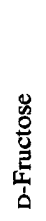 & 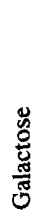 & 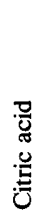 & 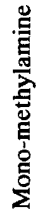 & 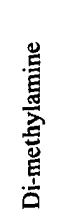 & 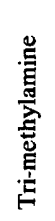 & $\sum_{i}^{J}$ & 岂 & 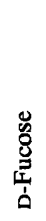 & 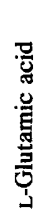 & 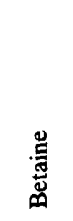 & 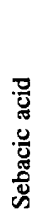 & 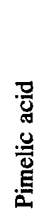 & 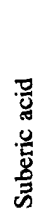 & 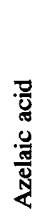 & 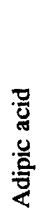 & \\
\hline Methylobacterium extorquens & - & - & - & - & - & - & + & - & - & - & - & - & + & + & - & - & - & - & - & - \\
\hline Methylobacterium organophilum & - & - & - & + & - & - & + & - & + & - & - & - & + & $-/ \mathbf{w}$ & - & - & - & - & - & - \\
\hline Methylobacterium rhodinum & - & - & - & + & - & + & + & - & - & - & - & - & + & + & - & - & - & - & - & - \\
\hline Methylobacterium rhodesianum & - & - & - & + & - & - & + & $+1-$ & - & - & - & - & + & $+1-$ & - & - & - & - & - & - \\
\hline Methylobacterium zatmanii & - & - & - & + & - & - & + & - & + & - & - & - & - & - & - & - & - & - & - & - \\
\hline Methylobacterium aminovorans & - & - & - & + & - & - & + & + & + & + & + & - & + & + & - & - & - & - & - & - \\
\hline Methylobacterium radiotolerans & + & + & + & - & + & + & - & - & - & - & - & + & + & + & + & + & + & + & + & + \\
\hline Methylobacterium mesophilicum & + & + & + & - & + & + & - & - & - & - & - & + & + & - & - & - & - & - & - & + \\
\hline Methylobacterium fujisawaense & + & + & + & - & + & + & - & - & - & - & - & + & + & - & - & - & - & - & - & + \\
\hline TK 0042 , TK 0043 & + & + & + & - & + & + & - & - & - & - & - & + & + & - & - & - & - & - & - & + \\
\hline TK 0038, TK 0037, TK 0044, TK 0045 & + & + & + & + & + & + & - & - & - & - & - & + & + & - & - & - & - & - & - & + \\
\hline TK 0040 & + & + & + & + & + & + & - & - & - & - & - & + & + & + & - & - & - & - & - & + \\
\hline
\end{tabular}


poration, and the complete tricarboxylic acid cycle is functional.

The type strain is TH-15, which was isolated from soil as a TMAH-utilizing bacterium by Urakami et al. in 1990 (35). This strain has all of the characteristics described above for the species. Its DNA base composition is $68.0 \mathrm{~mol} \% \mathrm{G}+\mathrm{C}$. The type strain has been deposited in the Japan Collection of Microorganisms, Institute of Physical and Chemical Research, as strain JCM 8240.

\section{REFERENCES}

1. Ando, S., S. Kato, and K. Komagata. 1989. Phylogenetic diversity of methanol-utilizing bacteria deduced from their 5S ribosomal RNA sequences. J. Gen. Appl. Microbiol. 35:351-361.

2. Austin, B., and M. Goodfellow. 1979. Pseudomonas mesophilica, a new species of pink bacteria isolated from leaf surfaces. Int. J. Syst. Bacteriol. 29:373-378.

3. Bligh, E. G., and W. J. Dyer. 1959. A rapid method of total lipid extraction and purification. Can. J. Biochem. Physiol. 37:911917.

4. Bousfield, I. J., and P. N. Green. 1985. Reclassification of bacteria of the genus Protomonas Urakami and Komagata 1984 in the genus Methylobacterium (Patt, Cole, and Hanson) emend. Green and Bousfield 1983. Int. J. Syst. Bacteriol. 35:209.

5. Bratina, B. J., G. A. Brusseau, and R. S. Hanson. 1992. Use of 16S rRNA analysis to investigate phylogeny of methylotrophic bacteria. Int. J. Syst. Bacteriol. 42:645-648.

6. Bulygina, E. S., V. F. Galchenko, N. I. Govorukhina, A. I. Netrusov, D. I. Nikitin, Y. A. Trotsenko, and K. M. Chumakov. 1990. Taxonomic studies on methylotrophic bacteria by $5 \mathrm{~S}$ ribosomal RNA sequencing. J. Gen. Microbiol. 136:441-446.

7. Colby, J., and L. J. Zatman. 1973. Trimethylamine metabolism in obligate and facultative methylotrophs. Biochem. J. 132:101112.

8. Goldberg, I., and A. P. Jensen. 1977. Phospholipid and fatty acid composition of methanol-utilizing bacteria. J. Bacteriol. 130: 535-537.

9. Goldberg, I., and R. I. Mateles. 1975. Growth of Pseudomonas C on $\mathrm{C}_{1}$ compounds: a correction. J. Bacteriol. 124:1028-1029.

10. Green, P. N. 1992. The genus Methylobacterium, p. 2342-2349. In A. Balows, H. G. Trüper, M. Dworkin, W. Harder, and K. H. Schleifer (ed.), The prokaryotes, a handbook on the biology of bacteria: ecophysiology, isolation, identification, applications, vol. 2, 2nd ed. Springer-Verlag AG, Berlin.

11. Green, P. N., and I. J. Bousfield. 1982. A taxonomic study of some gram-negative facultatively methylotrophic bacteria. J. Gen. Microbiol. 128:623-638.

12. Green, P. N., and I. J. Bousfield. 1983. Emendation of Methylobacterium Patt, Cole, and Hanson 1976; Methylobacterium rhodinum (Heumann 1962) comb. nov. corrig.; Methylobacterium radiotolerans (Ito and Iizuka 1971) comb. nov. corrig; and Methylobacterium mesophilicum (Austin and Goodfellow 1979) comb. nov. Int. J. Syst. Bacteriol. 33:875-877.

13. Green, P. N., I. J. Bousfield, and D. Hood. 1988. Three new Methylobacterium species: $M$. rhodesianum sp. nov., $M$. zatmanii sp. nov., and $M$. fujisawaense sp. nov. Int. J. Bacteriol. 38:124-127.

14. Hanson, R. S. 1980. Ecology and diversity of methylotrophic organisms. Adv. Appl. Microbiol. 26:3-39.

15. Heumann, W. 1962. Die Methodik der Kreuzung sternbildender Bakterien. Biol. Zentralbl. 81:341-354.

16. Hood, D. W., C. S. Dow, and P. N. Green. 1987. DNA:DNA hybridization studies on the pink-pigmented facultative methylotrophs. J. Gen. Microbiol. 133:709-720.

17. Hou, C. T., R. Patel, A. I. Laskin, and N. Barnabe. 1979. Microbial oxidation of gaseous hydrocarbons: epoxidation of $\mathrm{C}_{2}$ to $\mathrm{C}_{4} \mathrm{n}$-alkanes by methylotrophic bacteria. Appl. Environ. Microbiol. 38:127-134.

18. Ito, H., and H. lizuka. 1971. Taxonomic studies on a radioresistant Pseudomonas. XII. Studies on the microorganisms of cereal grain. Agric. Biol. Chem. 35:1566-1571.
19. Janota, L. 1950. Przebieg zuzymania Krasu Szczawiowego przez Pseudomonas extorquens Bassalik, w zaleznosci od poczatkowej liczby komorek. Med. Dosw. Mikrobiol. 2:131-132.

20. Kaneko, T., R. Nozaki, and K. Aizawa. 1978. Deoxyribonucleic acid relatedness between Bacillus anthracis, Bacillus cereus and Bacillus thuringiensis. Microbiol. Immunol. 22:639-641.

21. Kato, S., and K. Komagata. 1986. Nucleotide sequences of $5 \mathrm{~S}$ ribosomal RNAs of Protomonas extorquens, Rhodopseudomonas palustris, Rhodobacter capsulatus, and Enythrobacter longus. Nucleic Acids Res. 14:4371.

22. Kouno, K., and A. Ozaki. 1975. Distribution and identification of methanol-utilizing bacteria, p. 11-21. In Proceedings of the International Symposium on Microbial Growth on $\mathrm{C}_{1} \mathrm{Com}-$ pounds. Society of Fermentation Technology, Osaka, Japan.

23. Lidstrom-O'Connor, M. L., G. L. Fulton, and A. E. Wopat. 1983. 'Methylobacterium ethanolicum': a syntrophic association of two methylotrophic bacteria. J. Gen. Microbiol. 123: 3139-3148.

24. Lynch, M. J., A. E. Wopat, and M. L. O'Connor. 1980. Characterization of two facultative methanotrophs. Appl. Environ. Microbiol, 40:400-407.

25. Mizoguchi, T., T. Sato, and T. Okabe. 1976. New sulfuroxidizing bacteria capable of growing heterotrophically, Thiobacillus rubellus nov. sp. and Thiobacillus delicatus nov. sp. J. Ferment. Technol. 54:181-191.

26. Patel, R. N., C. T. Hou, and A. Felix. 1978. Microbial oxidation of methane and methanol: isolation of methane-utilizing bacteria and characterization of a facultative methane-utilizing isolate. $\mathrm{J}$. Bacteriol. 136:352-358.

27. Patt, T. E., G. C. Cole, and R. S. Hanson. 1976. Methylobacte rium, a new genus of facultatively methylotrophic bacteria. Int. J. Syst. Bacteriol. 26:226-229.

28. Rock, J. S., I. Goldberg, A. Ben-Bassat, and R. I. Mateles. 1976. Isolation and characterization of two methanol-utilizing bacteria. Agric. Biol. Chem. 40:2129-2135.

29. Romanovskaya, V. A., Y. R. Malashenko, and V. N. Bogachenko. 1978. Corrected diagnosis of the genera and species of methane-utilizing bacteria. Mikrobiologiya 47:120-130.

30. Saito, H., and K. Miura. 1963. Preparation of transforming deoxyribonucleic acid by phenol treatment. Biochim. Biophys. Acta 73:619-629.

31. Skerman, V. B. D., V. McGowan, and P. H. A. Sneath (ed.). 1980. Approved lists of bacterial names. Int. J. Syst. Bacteriol. 30:225-420.

32. Tamaoka, J., and K. Komagata. 1984. Determination of DNA base composition by reversed-phase high-performance liquid chromatography. FEMS Microbiol. Lett. 25:125-128.

33. Tonomura, K., T. Nakagami, F. Futai, and K. Maeda. 1968. Studies on the action of mercury-resistant microorganisms and the binding of mercurials to the cells. J. Ferment. Technol. 46:506-512.

34. Tsuji, K., H. C. Tsien, R. S. Hanson, S. R. DePalma, R. Scholtz, and S. LaRoche. 1990. 16S ribosomal RNA sequence analysis for determination of phylogenetic relationship among methylotrophs. J. Gen. Microbiol. 136:1-10.

35. Urakami, T., H. Araki, and H. Kobayashi. 1990. Isolation and identification of tetramethylammonium-biodegrading bacteria. J. Ferment. Bioeng. 70:41-44.

36. Urakami, T., H. Araki, H. Oyanagi, K. Suzuki, and K. Komagata. 1990. Paracoccus aminophilus sp. nov. and Paracoccus aminovorans sp. nov., which utilize $N, N$-dimethylformamide. Int. J. Syst. Bacteriol. 40:287-291.

37. Urakami, T., H. Araki, H. Oyanagi, K. Suzuki, and K. Komagata. 1992. Transfer of Pseudomonas aminovorans (den Dooren de Jong 1926) to Aminobacter gen. nov. as Aminobacter aminovorans comb. nov., and description of Aminobacter aganoensis sp. nov. and Aminobacter niigataensis sp. nov. Int. J. Syst. Bacteriol. 42:84-92.

38. Urakami, T., H. Kobayashi, and H. Araki. 1990. Isolation and identification of $N, N$-dimethylformamide-biodegrading bacteria. J. Ferment. Bioeng. 70:45-47.

39. Urakami, T., and K. Komagata. 1979. Cellular fatty acid composition and coenzyme Q system in Gram-negative methanol- 
utilizing bacteria. J. Gen. Appl. Microbiol. 25:343-360.

40. Urakami, T., and K. Komagata. 1981. Electrophoretic comparison of enzymes in the Gram-negative methanol-utilizing bacteria. J. Gen. Appl. Microbiol. 27:381-403.

41. Urakami, T., and K. Komagata. 1984. Protomonas, a new genus of facultatively methylotrophic bacteria. Int. J. Syst. Bacteriol. 34:188-201.

42. Urakami, T., and K. Komagata. 1984. Cellular fatty acid composition and quinone system in methane-utilizing bacteria and methanol-utilizing bacteria, p. 123-133. In R. L. Crawford and R. S. Hanson (ed.), The Proceedings of the Fourth International Symposium on Microbial Growth on $C_{1}$ compounds. American Society for Microbiology, Washington, D. C.

43. Urakami, T., and K. Komagata. 1986. Occurrence of isoprenoid compounds in Gram-negative methanol-, methane-, and methylamine-utilizing bacteria. J. Gen. Appl. Microbiol. 32:317-341.

44. Urakami, T., and K. Komagata. 1987. Cellular fatty acid com- position with special reference to the existence of hydroxy fatty acids in Gram-negative methanol-, methane-, and methylamineutilizing bacteria. J. Gen. Appl. Microbiol. 33:135-165.

45. Urakami, T., J. Tamaoka, and K. Komagata. 1985. DNA base composition and DNA-DNA homologies of methanol-utilizing bacteria. J. Gen. Appl. Microbiol. 31:243-253.

46. Urakami, T., J. Tamaoka, K. Suzuki, and K. Komagata. 1989. Paracoccus alcaliphilus sp. nov., an alkaliphilic and facultatively methylotrophic bacterium. Int. J. Syst. Bacteriol. 39:116121.

47. Whittenbury, R., and N. R. Krieg. 1984. Family IV. Methylococcaceae fam. nov., p. 256-261. In N. R. Krieg and J. G. Holt (ed.), Bergey's manual of systematic bacteriology, vol. 1. The Williams \& Wilkins Co., Baltimore.

48. Wolfrum, T., G. Gruner, and H. Stolp. 1986. Nucleic acid hybridization of pink-pigmented facultative methylotrophs and pseudomonads. Int. J. Syst. Bacteriol. 36:24-28. 